\title{
Preface for the Special Issue of Sustainable Manufacturing in 4th Industrial Revolution
}

\author{
Guest Editors: Friedrich Prinz', Doo-Man Chun², and Sung-Hoon Ahn" ${ }^{3 \#}$ \\ 1 Department of Mechanical Engineering, Stanford University, 450 Serra Mall, Stanford, CA, 94305, USA \\ 2 School of Mechanical Engineering, University of Ulsan, 93, Daehak-ro, Nam-gu. Ulsan, 44610, Republic of Korea \\ 3 Department of Mechanical and Aerospace Engineering, Seoul National University, 1, Gwanak-ro, Gwanak-gu, Seoul, 08826, Republic of Korea \\ \# Corresponding Author / E-mail: ahnsh@snu.ac.kr, TEL: +82-2-880-7110 \\ ORCID: 0000-0002-1548-2394
}

The industrialization began in the late 18th century by the 1 st Industrial revolution due to the development of steam power. A century later, mass production was possible by the 2 nd Industrial revolution due to electricity and assembly lines. In the late 20th century, the 3rd Industrial Revolution or the Digital Revolution began when information and communications technology developed.

However, industrialization in history is one of the main causes of pollution, and it was an unsustainable manufacturing model. In order to achieve sustainable manufacturing as well as maximum value creation, the new industrial model of the 4th Industrial Revolution or Industry 4.0 aims to be a viable and sustainable manufacturing with emerging technologies including artificial intelligence, big data, robotics, the Internet of Things, smart factory, 3D printing, and autonomous vehicles. The term of Industry 4.0 was proposed at the "2011 Hannover Fair" event in Germany and it started to create the concept of the 4 th Industrial Revolution.

The 4th Industrial Revolution is based on the 3rd Industrial Revolution, and technologies can be embedded and connected within machines, factories, societies and people. The 4th Industrial Revolution is fundamentally different from the previous three industrial revolutions derived mainly from inventions of specific technologies such as steam engine, technology for mass production, or information and communication technologies. The 4th Industrial Revolution includes a variety of emerging technologies, and it has great potential to connect people, machines, and technologies, improve the efficiency of manufacturing, create new business for personalized and customized products, and minimize damage to the environment throughout the product lifecycle.

In the 4th Industrial Revolution, "Smart Factory" is an important concept for sustainable manufacturing. In smart factories, cyberphysical systems use a virtual world reflecting the physical world to evaluate actual physical manufacturing processes and make decentralized, self-optimized decisions. Over the Internet of Things, smart factories cooperate with each other and respond to the internal and external demands in real time. In smart factories, connected manufacturing systems can also take into consideration demands on sustainability such as minimizing waste, effectively utilizing natural resources, and maximizing the efficiency of energy use.

The papers in this special issue discuss recent research topics on the fields of sustainable manufacturing in 4th industrial revolution. Below are the topics in this special issue:

- Smart factory

- 3D printing

- Sensors and actuators for robotics

- Energy saving and energy harvesting in smart factory/city

- Sustainable industrial value creation

- Design automation

We would like to express our sincere appreciation to all the authors and editorial members for their precious effort, and to Ms. Sung Gyung Lee of Korean Society for Precision Engineering (KSPE) for her dedicated support during the review and production processes. 